\title{
EFEKTIVITAS MODEL PENGINTEGRASIAN STRATEGI AFEKTIF DALAM PEMBELAJARAN MATAKULIAH WICARA INDIVIDU PRODI PENDIDIKAN BAHASA DAN SASTRA IKIP BUDI UTOMO MALANG
}

\author{
ARTIFA SORRAYA \\ IKIP Budi Utomo Malang \\ Email: arrtiefa.soerraya@gmail.com
}

\begin{abstract}
Absrtact: Learning strategies are steps taken by students to improve their own learning. Learning strategy is desired learners to achieve certain goals and manifest in various types. The use of this learning strategy appears in the specific actions or behaviors that the learners do to improve their language skills, for example by imitating, repeating, transferring into other languages, improving speech, asking for clarification, and so on. This research is more emphasis on affective strategy. This strategy refers to feelings, attitudes, motivations and values. There are three main sets of affective strategies (demeaning your worries, pushing yourself, and getting your emotional temperature). The general objective of this research is to describe the effectiveness of the model of affective strategy integration in learning subject course of Indonesian language and literature study program IKIP Budi Utomo Malang. Specifically, the purpose of this study is to obtain a significant description of the difference between the verbal skills in the 2014A and 2014B classes of Indonesian language and literature education programs IKIP Budi Utomo Malang and obtain a significant description of the difference in effectiveness between the learning ability of speech before and after. This research uses experimental design with non equivalent control group design. The data analysis technique used to find the difference is using paired paired test formula for one sample and t test of the independent variable for different samples. The sample of this research is student of class of 2014A and 2014B of Indonesian language and literature education program IKIP Budi Utomo Malang. Experiments were conducted by dividing experimental and control groups. The experimental group is a student of Indonesian language and literature education program class of 2014A, while the control group is a student of language and literature education program class of 2014B, by taking pretest value and postes value. Based on the research that has been done, the result of pretest in the experimental group is still low with an average of 56,375 after being given affective strategy treatment on average value rose 20,25 points to 76,625, while the mean in control group at pretest 58,38 up 0,222 points at the postes being 58.61. The effectiveness between the postes value of the experimental group and the control group is very different. In the control group the score also increased but more increase in the experimental group. It shows the model of affective strategy integration in learning subject course of individual speech of Indonesian language and literature education program IKIP Budi Utomo Malang. From the research findings, the researcher suggested that lecturers in the environment of IKIP Budi Utomo Malang should implement learning strategies to improve student achievement and students do not feel bored.
\end{abstract}

Keywords: effectiveness, affective strategies, speech learning

Strategi belajar merupakan langkahlangkah yang diambil oleh para siswa untuk meningkatkan pembelajaran mereka sendiri. Strategi belajar diinginkan pembelajar untuk mencapai tujuan tertentu dan terwujud dalam berbagai jenis. Penggunaan strategi belajar ini tampak pada tindakan-tindakan atau perilakuperilaku khusus yang dilakukan pembelajar untuk meningkatkan kemampuan bahasanya, misalnya dengan cara meniru, mengulang-ulang, mentransfer kedalam bahasa lain, memperbaiki tuturan, meminta klarifikasi, dan lain-lain.
Sebagai contoh, seorang siswa memperbaiki tuturan teman yang diketahuinya salah atau kurang baik. Tindakan-tindakan ini dapat diamati dalam petilaku berbahasa anak pada saat berinteraksi dengan mitra tuturnya. Menurut Oxford (1990) perilaku tersebut dipengaruhi oleh beberapa karakteristik umum, seperti perkembangan usia, kemampuan bahasa, kondisi psikologis pembelajar bahasa.

Penelitian ini lebih menekankan pada strategi afektif. Strategi ini mengacu pada perasaan, sikap, motivasi dan nilai. Ada tiga 
rangkaian utama strategi afektif (merendahkan kekhawatiran Anda, mendorong diri sendiri, dan mendapatkan suhu emosional Anda). Sisi afektif pembelajar merupakan salah satu pengaruh yang terbesar pada keberhasilan atau kegagalan pembelajar bahasa yang baik seringkali adalah pembelajar yang mengetahui bagaimana mengendalikan emosi dan sikap mereka terhadap pembelajaran. Perasaan negatif dapat menghentikan perkembangan bahkan untuk pembelajaar yang memahami suatu bahasa baru. Emosi dan sikap positif dapat menjadikan pembelajaran bahasa jauh lebih efektif dan menyenangkan. Para guru dapat menerapkan pengaruh yang luar biasa melalui atmosfer emosional didalam kelas dengan tiga cara yang berbeda: dengan merubah struktur sosial kelas untuk memberikan lebih banyak tanggung jawab kepada murid, dengan memberikan jumlah komunikasi alamiah yang lebih banyak, dan mengajarkan para pembelajar menggunakan strategi-srategi afektif.

Tanpa disadari, selama ini pembelajaran di sekolah-sekolah dengan strategi yang kurang tepat dapat membuat suasana kelas menjadi tidak kondusif. Oleh karena itu, penggunaan strategi belajar yang tepat bagi siswa sangatlah penting untuk menunjang keberhasilan dalam mencapai tujuan yang diinginkan. Berdasarkan pengamatan yang dilakukan peneliti terhadap pembelajaran matakuliah wicara individu, diperoleh informasi mengenai model yang digunakan oleh dosen dalam menyampaikan materi kurang menyeluruh terhadap semua siswa. Hal ini dibuktikan dengan hasil penelitian mahasiswa pada aspek berbicara tidak sesuai dengan apa yang diharapkan, yaitu mahasiswa kurang mampu mencapai kompetensi yang diinginkan. Oleh karena itu, strategi afektif digunakan peneliti agar membantu mahasiswa dalam berkomunikasi seperti pemahaman pendengaran, pemahaman bacaan dan produksi lisan, terutama dalam aspek berbicara.

Alasan peneliti mengangkat permasalahan tersebut sebagai objek penelitian dengan judul Efektivitas Pengimplementasian Model Pengintegrasian Strategi Afektif dalam Pembelajaran Matakuliah Wicara Individu Prodi Pendidikan Bahasa dan Sastra Indonesia IKIP Budi Utomo Malang, karena peneliti ingin mengetahui sejauh mana strategi afektif dapat mendukung efektivitas kemampuan wicara mahasiswa terutama ketika berpidato. Penelitian ini diharapkan mampu membuat guru memahami seberapa penting penggunaan strategi belajar yang diterapkan dalam pembelajaran.

\section{METODE}

Peneliti dapat menggunakan metode yang sesuai dengan penelitian yang akan dipakai tergantung pada tujuan penelitian. Penelitian ini bertujuan untuk mengetahui bagaimanakah efektivitas model pengintegrasian strategi afektif dalam pembelajaran matakuliah wicara individu prodi pendidikan bahasa dan sastra Indonesia IKIP Budi Utomo Malang, maka penelitian ini termasuk penelitian eksperimen. Penelitian eksperimental merupakan penelitian yang paling murni kuantitatif, karena semua prinsip dan kaidah-kaidah penelitian kuantitatif dapat diterapkan dalam metode ini. Metode ini bersifat validation atau menguji (Krathwohl 1997,h. 7), yaitu menguji pengaruh satu atau lebih variabel terhadap variabel yang lain. Variabel yang memberi pengaruh dikelompokkan sebagai variabel bebas (independent variables), dan variabel terikat (dependent variables).

Penelitian ini bersifat menguiji, maka semua variabel yang diuji harus diukur dengan menggunakan instrumen pengukuran atau tes yang sudah distandardisasikan atau dibakukan. Pembakuan instrumen dan pengelolahan hasil penelitian diolah dengan menggunakan analisis statistik inferensial-parametrik. Untuk menguji apakah perubahan yang terjadi pada variabel terikat itu akibat dari variabel bebas, dan bukan karena variabel-variabel yang lainnya, maka semua variabel lain diluar variabel menyamakan karakteristik sampel dalam variabel-variabel tersebut. Ada beberapa variasi dari penelitian eksperimental, yaitu: eksperimen murni, eksperimen kuasi, ekperimen lemah dan subjek tunggal (Sukmadinata,2011:57).

Peneliti tidak selalu dapat melakukan pemilihan subjek secara random (random assignment), peneliti tidak memungkinkan memilih dan memilah subjek sesuai dengan rancangannya.Penelitian ini menggunakan rancangan eksperimen (quasi eksperimental design) dengan jenis rancangan kelompok kontrol yang tak sama (non equivalent control group design). Peneliti menggunakan kelas yang sudah ada dari Perguruan tinggi yang digunakan kelas sebagai subjek penelitian, yakni angkatan 2014A dan 
2014B. Peneliti tidak memungkinkan membuat kelas sendiri karena waktunya yang terbatas dari pihak sekolah. Penelitian ini, yang merupakan variabel bebasnya adalah pengimplemantasian model pengintegrasian strategi afektif, sedangkan variabel terikatnya adalah kemampuan wicara angkatan 2014.

Rancangan kelompok nonequivalen sering dipakai dalam penelitian. Rancangan ini,subjek penelitian atau partisipan penelitian tidak dipilih secara acak untuk dilibatkan dalam kelompok eksperimen dan kelompok kontrol. Pada dasarnya, langkah-langkah dalam rancanagn ini sama seperti pada rancangan pretest-posttest experimental control group design. Rancangan ini, ada dua kelompok subjek satu mendapat perlakuan dan satu kelompok sebagai kelompok kontrol. Keduanya memperoleh prates dan pascates. Perbedaan dengan kelompok nonequivalen, bahwa kelompok tidak dipilih secra acak tau random. Rancangan kelompok nonequivalen ini disebut juga sebagai unteated control group design with pretes-and posttest. Rancangan penelitian ini dikategorikan sebagai rancangan eksperimen kuasi (quasi experimental design). Rancangan ini sangat sering dipakai dalam penelitian.

Rancangan diatas (rancangan kuasieksperimen) tidak menggunakan random assignment sehingga kelemahan-kelemahan jika dibandingkan rancangan eksperimen yang sebenarnya. Namun demikian, rancangnan ini dilakukan dengan jadwal perlakuan pengamatan yang amat cermat. Rancangan ini memberikan landasan yang kuat untuk memberikan alasan untuk mengendalikan ancaman yang berkaitan dengan validitas internal. Sebagaimana kita saksikan diatas, rancangan diatas tidak melakukan random terhadap kelompok subjek bahwa garis putus-putus diantara kedua kelompok menunjukkan kelompokm-kelompok yang ditetapkan tidak dipilih secara random (Setyosari, 2012:177). Penelitian ini menggunakan pendekatan kuantitatif.

Sampel adalah sebagian atau wakil populasi yang diteliti, dinamakan penelitian sampel apabila kita bermaksud untuk menggeneralisasikan hasil penelitian sampel, yang dimaksud menggeneralisasikan adalah mengangkat kesimpulan penelitian sebagai suatu yang berlaku bagi populasi (Arikunto, 2010:174-175). Penelitian ini menggunakan sampel angkatan 2014A dan 2014B prodi pendidikan bahasa dan sastra Indonesia IKIP Budi Utomo Malang. Instrumen adalah alat yang digunakan untuk megumpulkan data (Arikunto, 2010:265). Untuk menjaring data maka dapat digunakan 2 macam instrumen, instrumen tersebut berkedudukan sebagai pengumpul instrument. Instrumen penelitian ini berupa tes dan observasi. Tes adalah serentetan pertanyaan atau latihan atau alat lain yang digunakan untuk mengukur keterampilan, pengetahuan, intelegensi, kemampuan atau bakat yang dimiliki oleh individu atau kelompok (Wahyuni, 2002:13).

Instrumen tes ini digunakan untuk mengetahui dan mengukur efektivitas sebelum dan sesudah diimplementasi model pengintegrasian strategi afektif dalam pembelajaran matakuliah wicara prodi pendidikan bahasa dan sastra Indonesia IKIP Budi Utomo Malang. Validitas tes, mengarah pada ketepatan interpretasi hasil penggunaan suatu prosedur evaluasi sesuai dengan tujuan pengukurannya (Grondlund, 1985). Validitas merupakan suatu keadaan apabila suatu instrumen evaluasi (misalnya tes) dapat mengukur apa yang sebenarnya harus diukur secara tepat (Wahyuni 2008). Suatu tes hasil belajar dikatakan valid apabila tes tersebut benar-benar mengukur hasil belajar bahasa. Validitas tidak semata-mata berkaitan dengan kedudukan tes sebagai alat, melainkan terutama padakesesuaian hasilnya, sesuai dengan tujuan penyelenggarakan tes.

Berdasarkan instrumen penelitian tersebut, validitas yang digunakan adalah validitas ukuran yang menunjuk pada pengertian seberapa jauh siswa yang sudah diajar dalam bidang bahasa yang menunjukkan kemampuan yang lebih tinggi daripada yang belum diajar. Untuk menguji validitas ukuran adalah dengan mengujikan sebuah tes pada subjek yang sama pada waktu yang berbeda. Tes pertama dilakukan sebelum mahasiswa diberi pelajaran yang diteskan itu (pretes), dan kedua setelah mahasiswa selesai diajar pelajaran itu (postes). Signifikasi perbedaan nilai rata-rata siswa antara pretes dan postes itulah yang diuji dengan teknik t-tes. Selain menggunakan uji validitas berpasangan untuk satu sampel, digunakan untuk mengetahui perbedaan antara prates dan pascates atau sebelum diajar dan 
sesdudah diajar, menggunakan uji validitas uji t variabel bebas atau yang beda sampel, karena perbedaan antara nilai postes dari kelompok eksperimen atau kelompok yang diberi perlakuan dan kelompok kontrol atau kelompok yang tidak mendapatkan perlakuan.

Observasi adalah teknik penilaian dengan cara mengamati tingkah laku pada situasi tertentu (Sanjaya, 2006: 190). Menurut Sanjaya Wiraatmaja (2006: 49) observasi dilakukan untuk mengikuti kegiatan pembelajaran di dalam kelas. Jadi dalam penelitian ini untuk menjawab rumusan masalah nomer satu dan dua menggunakan ujicoba validitas ukuran dengan cara kedua karena sampel yang berbeda. Sedangkan untuk rumusan masalah yang nomer tiga menggunakan uji coba validitas yang pertama karena sampelnya berbeda.

\section{HASIL}

Analisis data dalam penelitian ini dilakukan untuk memberikan jawaban terhadap rumusan masalah yaitu (1) Bagaimanakah kemampuan wicara mahasiswa kelas eksperimen prodi pendidikan bahasa dan sastra Indonesia IKIP Budi Utomo Malang? (2) Bagaimanakah kemampuan wicara mahasiswa kelas kontrol prodi pendidikan bahasa dan sastra Indonesia IKIP Budi Utomo Malang?, (3) Bagaimanakah perbedaan kelas eksperimen dengan kelas kontrol prodi pendidikan bahasa dan satra Indonesia IKIP Budi Utomo Malang?. Data yang terkumpul dalam penelitian eksperimen ini yang menggunakan rancangan penelitian eksperimen kuasi (quasi experimental design), dan menggunakan jenis rancangan kelompok nonekuivalen yaitu kedua kelompok yang dipilih tidak secara acak atau random, pada awalnya diberikan pretes. Bedanya kelompok yang satu diberi perlakuan, sedangkan kelompok yang lain tidak dikenai perlakuan melainkan dijadikan atau perlakuan sebagai kelompok kontrol (Setyosari, 2010:180).

Paired samples statistics menunjukkan ringkasan dari rata-rata dan standar deviasi dari kedua perbandingan. Rata-rata nilai prates adalah 56,375 dan rata-rata nilai postes adalah 76,625 meningkat 20,25 poin. Output paired sample correlations menunjukkan hasil korelasi antara dua buah sampel yaitu 0,894 dengan angka probabilitas 0,000 (di bawah 0,05). Ini berarati hubungan antara sebelum dan sesuadah mengimplementasikan strategi afektif pada ketrampilan berbicara adalah nyata dan cukup erat.

Dari output dapat diketahui bahwa mean sebesar 2,025 dengan standar deviasinya 6,547. Nilai $t$ hitung sebesar 12,372 lebih tinggi dari $t$ tabel sebesar 1,753 . Sedangkan nilai sig ( 2 tailed) sebesar $0,000<0,05$. Sehingga dapat disimpulkan bahwa Ho ditolak yang berarti kemampuan berbicara ada perbedaan sebelum dengan sesudah mengimplementasikan strategi afektif.

Paired samples statistics menunjukkan rngkasan dari rata-rata dan standar deviasi dari kedua perbandingan. Rata-rata nilai prates adalah 58,3889 dan rata-rata nilai postes adalah 58,6111 meningkat 0,2222 poin. Tapi dibandingkan dengan kelas VIIIA (kelompok eksperimen), yang meningkat 20,25 poin. Kelompok 1 atau kelompok eksperimen lebih banyak peningkatan dari pada kelompok 2 atau kelompok kontrol. Ini menunjukkan bahwa dengan mengintegrasikan strategi afektif efektif.

Output paired sample correlations menunjukkan hasil korelasi antara dua buah sampel yaitu 0,991 dengan angka probabilitas 0,000(dibawah 0,005). Ini berarti ada hubungan antara tes sebelum dengan sesudah. Tetapi dibandingkan dengan korelasi kelompok 1, kelompok 2 lebih sedikit korelasinya yang tanpa diintegrasi dengan strategi afektif.

Dari output dapat diketahui bahwa mean sebesar 0,22222 dengan standar daviasi 1,26284. Nilai t hitung sebesar 0,747 lebih kecil dari t tabel sebesar 1,740. Sedangkan nilai sig (2 tailed) sebesar 0,466 >0,05. Sehingga dapat disimpulkan bahwa Ho diterima yang berarti kemampuan berbicara tidak ada perbedaan antara sebelum dengan sesudah pada kelompok kontrol di kelas VIII B.

Group Statistics menunjukkan ringkasan dari rata dan standar deviasi dari kedua perbandingan. Rata-rata nilai postes yang mendapatkan treatment atau kelas 2014 A adalah 76,62 dan rata-rata postes yang tidak mendapatkan treatmen atau kelompok kontrol kelas 2014 B adalah 58,58. Dari rata-rata dapat diketahui bahwa rata-rata kelompok yang mendapatkan treatment atau kelas 2014 A lebih tinggi dari pada rata-rata kelompok kontrol atau kelompok yang tidak mendapatkan treatment di kelas 2014 B. 
Karena hasil Lavene's Tes di atas menyatakan bahwa asumsi kedua variance tidak sama besar (Equal variances not assumed) untuk hipotesis Ho: $\mu 1=\mu 2$ yang memberikan nilai $t=$ 7,167 dengan derajad kebebasan $=26,753$ dan $p$ value $(2$ tailed $)=0,000$. Karena $p$-value $=0,000$ lebih kecil dari á=0,05 maka Ho: $\mu 1=\mu 2$ ditolak. Sehingga dapat disimpulkan bahwa purata (mean) kelompok eksperimen dan kelompok kontrol berbeda.

\section{PEMBAHASAN}

Pembahasan ini dikemukakan temuantemuan selama penelitian berlangsung, yakni penelitian pada kelompok eksperimen (dengan mengimplementasikan strategi afektif) dan kelompok kontrol(tanpa mengimplementasikan strategi afektif) dalam pembelajaran wicara dalam berpidato. Pada dasarnya strategi afektif itu memang cocok untuk mengurangi rasa kegelisahan atau rasa kekhawatiran siswa dalam pembelajaran berbicara bahasa Indonesia bukan hanya itu tapi strategi afektif mendorong diri mahasiswa atau memotivasi mahasiswa. Sebelum siswa mendapatkan materi pelajaran siswa melakukan relaksasi progesif, bernafas dalam-dalam atau meditasi, menggunakan musik, menggunakan tawa, itu semua adalah langkah-langkah agar siswa merasa santai dan mengurangi kegelisahan atau kekhawatirannya. Selain itu strategi afektif juga mendorong diri sendiri dengan memotivasi diri sendiri agar bisa atau sudah siap untuk menerima pelajaran yang akan diajarakan oleh guru.

\section{KESIMPULAN}

Berdasarkan Paired samples statistics pada kelompok ekperimen menunjukkan ringkasan dari rata-rata dan standar deviasi dari kedua perbandingan. Rata-rata nilai prates adalah 56,375 dan rata-rata nilai postes adalah 76,625 meningkat 20,25 poin. Jika dihitung manual menggunakan uji validitas ukuran sampel yang sama(berpasangan), dalam keputusan disebutkan bahwa "karena harga statistik $=7,558$ $>\mathrm{t}$ tabel $=2,131$, maka terdapat perbedaan yang signifikan antara XI dan X2 atau prates dan postes".

Berdasarkan Paired samples statistics pada kelompok kontrol menunjukkan ringkasan dari rata-rata dan standar deviasi dari kedua perbandingan. Rata-rata nilai prates adalah
58,3889 dan rata-rata nilai postes adalah 58,6111 meningkat 0,2222 poin. Tapi dibandingkan dengan kelas 2014A (kelompok eksperimen), yang meningkat 20,25 poin. Kelompok 1 atau kelompok eksperimen lebih banyak peningkatan dari pada kelompok 2 atau kelompok kontrol. Ini menunjukkan bahwa dengan mengimplementasikan strategi afektif efektif. Dan jika dihitung manual menggunakan uji validitas ukuran dengan sampel yang sama(berpasangan), dalam keputusan disebutkan bahwa "karena harga statistik $=0,0233<\mathrm{t}$ tabel $=2,110$, maka tidak terdapat perbedaan yang signifikan antara XI dan X2 atau prates dan postes".

Dari hasil Lavene's Tes di atas menyatakan bahwa asumsi kedua variance tidak sama besar (Equal variances not assumed) untuk hipotesis Ho: $\mu 1=\mu 2$ yang memberikan nilai $t=7,167$ dengan derajad kebebasan $=26,753$ dan $p$-value $(2$ tailed) $=0,000$. Karena $p$-value $=0,000$ lebih kecil dari á =0,05 maka Ho: $\mu 1=\mu 2$ ditolak. Dan jika dihitung manual menggunakan uji validitas ukuran dengan sampel yang berbeda bahwa "karena harga statistic $=7,0173>\mathrm{t}$ tabel 2,036, maka terdapat perbedaan yang signifikan antara X1(postes pada kelompok eksperimen) dan X2(postes pada kelompok kontrol). Sehingga dapat disimpulkan bahwa purata (mean) kelompok eksperimen dan kelompok kontrol berbeda. Lebih tinggi purata(mean) pada kelompok eksperimen dari pada kelompok kontrol. Dan dapat disimpulkan bahwa pembelajaran matakuliah wicara individu prodi pendidikan bahasa dan sastra Indonesia IKIP Budi Utomo Malang dengan mengintegrasikan dengan strategi afektif sangat afektif dan dapat meningkatkan hasil belajar pembelajaran wicara mahasiswa angkatan 2014 prodi pendidikan bahasa dan sastra Indonesia IKIP Budi Utomo Malang.

\section{SARAN}

Dari hasil-hasil penelitian yang didapatkan oleh peneliti selama dan setelah berlangsungnya proses penelitian, peneliti mencoba mengemukakan saran-saran berikut ini.

1) Dosen pengampu prodi pendidikan bahasa dan sastra Indonesia

Sesuai dengan teori yang telah dibuktikan kebenarannya oleh peneliti menunjukkan 
pembelajaran berbicara mengomentari kutipan novel remaja dengan mengimplementasikan strategi afektif dapat mengefektifkan pembelajaran matakuliah wicara individu dan dapat membantu dan meningkatkan hasil belajar berbicara mahasiswa di depan kelas. Guru bahasa dan sastra Indonesia, hendaknya dapat memilih dan menggunakan strategi pembelajaran yang tepat dan sesuai demi peningkatan hasil belajar bahasa dan sastra Indonesia oleh mahasiswa.

2) Bagi peneliti selanjutnya

Diharapkan bahwa penelitian ini dapat berguna sebagai bahan pertimbangan untuk mengadakan penelitian lebih lanjut, bukan hanya pembelajaran berbicara saja tetapi ketrampilan yang lain, misalnya menyimak, menulis, dan membaca.

\section{DAFTAR RUJUKAN}

Oxford, R.I.1990. Language Learning Strategies: What Every Teacher Should Know. New York: Newbury House Publishers.

Wahyuni, S. 2008. Evaluasi Pembelajaran Bahasa. Malang: Universitas Islam Malang.

Ghazali, S. 2010. Pembelajaran Ketrampilan Berbahasa Dengan Pendekatan
Komunikatif-Interaktif. Malang: PT Refika Aditama.

Sunendar, D. 2011. Strategi Pembelajaran Bahasa. Bandung: PT Remaja Rosdakarya.

Arikunto, S. 2010. Prosedur Penelitian Suatu Pendekatan Praktik. Jakarta: PT Rineka Cipta.

Rahardi, M., dkk. 2000. Statistik Pendidikan. Bandung: CV Pustaka Setia.

Setyosari, P. 2012. Metode Penelitian Pendidikan dan Pengembangan. Jakarta: Kencana Prenada Media Group.

Tarigan, G. 2008. Berbicara Sebagai Keterampilan Berbahasa. Bandung: Angkasa Bandung.

Slameto. 2010. Belajar dan Faktor-faktor yang Mempengaruhi. Jakarta: Rineka Cipta.

Sukmadinata, S. 2011. Metode Penelitian Pendidikan. Bandung: PT Remaja Rosdakarya.

Uno, H. 2011. Teori Motivasi dan Pengukurannya. Analisis di Bidang Pendidikan. Jakarta: Bumi Aksara.

Uyanto, S. L. S. 2009. Pedoman Analisis Data dengan SPSS. Jakarta: Graha Ilmu. 